\title{
Experienced speeds of fixed Internet connections as drivers of customer bonds with their provid- er - An empirical study of consumers in Germany
}

\author{
Torsten J. Gerpott ${ }^{\mathrm{a}^{*}}$
}

${ }^{a}$ Chair of Strategic and Telecommunications Management, Mercator School of Management, University of Duisburg-Essen, Lotharstr. 65, 47057 Duisburg, Germany

\section{CH R O N I C L E}

\section{Article history:}

Received: September 19, 2018

Received in revised format: Sep-

tember 20,2018

Accepted: October 3, 2018

Available online:

October 3, 2018

Keywords:

Bandwidth

Internet access

Propensity to churn

Quality of experience

Service satisfaction

Transmission speed

Wireline broadband service

\section{A B S T R A C T}

\begin{abstract}
Management practitioners often assume that raises in the contractual absolute maximum bandwidth of Internet connections increase the attitudinal bonds of customers with their access provider. The present study challenges this perspective: In a sample of up to 752 German-speaking Internet users with a wireline Internet access at home, it explores two relative speed characteristics of broadband connections (customer quality experiences in terms of delivered transmission speeds (1) relative to the maximum down- and upload bandwidths as per customer contract, and (2) relative to speeds emphasized in advertisements of a consumer's access provider) as potential determinants of customer affinity with an access provider. Furthermore, correlations are analyzed between the frequency with which customers use speed tests to check the quality of their wireline Internet connection and their attitudinal bonds with their access provider. Multivariate regression analysis reveals that the impression that advertised wireline access bandwidths are exaggerated compared to the speeds actually delivered and - to a lesser extent - the perception that the contractual maximum speed is reached only in a low share of a customer's Internet sessions significantly decrease customer satisfaction and significantly increase customer inclination to churn. The effects of the two speed assessments are not independent of one another: Perceived speed exaggerations in a provider's ads impair customer bonds less (more) strongly if the experienced share of Internet sessions with speeds below the contractual maximum bandwidth is high (low). More frequent speed testing reduces customer bonding, especially in case that advertised speeds of a customer's provider are experienced as overblown.
\end{abstract}

\section{Introduction}

The number of persons who access the Internet from home has soared over the last 25 years. According to the ITU (2017), worldwide the number of Internet users increased from 2.0 billion at the end of 2010 to 3.6 billion at the end of 2017. This corresponds to an annual growth rate of $8.8 \%$ alone during this seven-year period. Hence, it should not come as a surprise that the number of empirical studies on factors influencing the attitudinal bonds of consumers with their Internet access service provider raised accordingly. In this context, the construct of attitudinal bonding encompasses both the satisfaction of customers with their Internet connection (provider) and the propensity to maintain the contractual relationship with their supplier or to terminate it at the next occasion (Gerpott et al., 2001).

* Corresponding author. Tel.: +49 2033793109 , Fax +49 2033792656

E-mail address: torsten.gerpott@uni-due.de (T. J. Gerpott) 
Studies in this field indicate that the technical quality of Internet connections is a key driver of the emotional bonds consumers form with their access provider. Here, the complex issue of access quality is primarily narrowed down to objectively measured or subjectively experienced download and upload transmission speeds of Internet connections (e.g., Quach et al., 2016; Thaichon et al., 2014; for a comprehensive review of quality parameters of Internet access services see Gerpott, 2017a). All in all, the empirical literature suggests that the bandwidth of Internet connections and the inversely correlated waiting time in receiving or sending data tend to have significant positive and negative, respectively, effects on attitudinal bonds of customers with the provider of their network connection or a website/application which they are accessing (e.g., Dobholkar \& Sheng, 2008; Giovanis et al., 2014; Grzybowski et al., 2018). The classification of connection speed as an extraordinarily important quality feature is reflected in the fact that national regulatory authorities, companies and civil-society organization alike offer so-called "speed tests" already for a number of years. Such testing instruments enable users to measure the transmission rates they actually get from their Internet connection supplier (Bundesnetzagentur, 2018a; Elkins, 2018; Klink et al., 2012; Mansmann, 2009; Ofcom, 2016).

To date, both management practitioners and scholars implicitly assume that the objectively measured or subjectively experienced absolute maximal down- and upload bandwidths of an Internet connection positively affects the psychological bonds of consumers with their Internet access service provider. The present paper takes a different stance. It contributes to the literature by analyzing correlations between two customer-perceived relative or reference-dependent speed/quality facets of Internet connections (experienced transmission rates relative to (1) the contractually specified maximum speed and (2) bandwidth claims in provider ads) on the one hand and the attitudinal affinity of consumers with their connection provider on the other hand. In this way it extends the state of scientific knowledge about antecedents of consumer bonds with Internet access service suppliers. Further, the investigation helps to derive empirically founded recommendations for Internet connection providers concerning the communication of bandwidth attributes of their services.

The remainder of this article is structured as follows: Section 2 explains the focal speed concepts of the analysis to derive three research hypotheses. Section 3 describes the data collection procedure, the sample and the measurement of the study variables. Subsequently we report the results of the empirical hypotheses tests in section 4. Section 5 discusses implications of our findings for management practice and future research.

\section{Conceptual background and research hypotheses}

The emphasis of prior research on impacts of (objectively measured or subjectively experienced) absolute down- and upload speeds of Internet connections on indicators of the attitudinal affinity of consumers with their access provider is somewhat perplexing because general consumer behavior theories and empirical studies likewise suggest that customers evaluate quality dimensions of purchased services relative to reference points (Gneezy et al., 2014; Jha \& Balaji, 2015). With regard to the speed of Internet connections, relevant reference points that access providers can directly shape stem from the maximal bandwidth that suppliers commit in their customer contracts or from speed claims that they highlight in advertisements. ${ }^{1}$ With a look at the contractually specified maximum speeds ("up to data rates") investigations conducted by telecom sector regulators or broadband technology specialists reveal that on average connection rates that consumers actually get from their provider frequently fall far below the contractually mentioned maximal speed boundaries (Bundesnetzagentur, 2018b; Bünder \& Jansen, 2018a; FCC, 2016; Grubesic, 2015; Reuter, 2018). In Germany as the focal country of the pre-

\footnotetext{
${ }^{1}$ In addition, there are other reference points such as, in particular, the download and upload rates of connections of competitors (Buoye, 2016). However, they differ from the focal yardsticks of the present work in that they can not be directly designed by an Internet user's access provider.
} 
sent research, four recent studies commissioned by the Bundesnetzagentur show in large samples of persons with a fixed broadband connection that objectively measured download speeds reached the threshold of $100 \%(50 \%)$ of the maximal contractual download bandwidth for less than $20 \%(80 \%)$ of the participants (see Table 1, bloc 1). Furthermore, the Bundesnetzagentur speed research indicates that the ratio between actually supplied to contractually communicated maximum download speeds $(=$ "delivery reliability") is (1) somewhat lower for people who reside in rural areas compared to participants with a semi-urban or urban place of residence and (2) has declined over time (see Table 1, blocs I.1 to I.3). For consumers accessing the Internet via mobile radio networks the speed-related delivery reliability of connection providers is even worse than for customers with a fixed-line access (see Table 1, bloc II). The delivery reliability of Internet connection providers in Germany is poor compared to many other countries (FCC, 2016; Grubesic, 2015; Ofcom, 2018) Thus, economic policy actors and business journalists alike use harsh words (e.g., "bandwidth cheat") to critically portray the German situation in terms of unmet broadband promises (Bünder \& Jansen, 2018b; Klingbeil, 2017).

\section{Table 1}

Share of users with a measurement of at least $\mathrm{x} \%$ of the contractually specified maximum download rate

\begin{tabular}{|c|c|c|c|c|c|}
\hline \multirow{2}{*}{\multicolumn{2}{|c|}{$\begin{array}{l}\text { Group covered/ } \\
\text { survey period }\end{array}$}} & \multirow[t]{3}{*}{$\begin{array}{l}\text { Number } \\
\text { of observations }\end{array}$} & \multicolumn{3}{|c|}{$\begin{array}{c}\text { Share of users getting } \geq x \% \text { of the contractually agreed } \\
\text { maximum download rate }\end{array}$} \\
\hline & & & \multirow[t]{2}{*}{$x=\mathbf{5 0} \%$} & \multirow[t]{2}{*}{$x=70 \%$} & \multirow[t]{2}{*}{$x=100 \%$} \\
\hline I. & $\begin{array}{l}\text { All participants with a } \\
\text { fixed-line connection }^{\mathrm{a}}\end{array}$ & & & & \\
\hline & $-\quad 21.05 .2012$ to 31.12 .2012 & 219,830 & $69.7 \%$ & $53.0 \%$ & $19.5 \%$ \\
\hline & $-\quad 01.07 .2013$ to 31.12 .2013 & 147,125 & $78.0 \%$ & $63.0 \%$ & $15.9 \%$ \\
\hline & $-\quad 01.10 .2016$ to 30.09 .2017 & 437,192 & $71.6 \%$ & $58.7 \%$ & $12.0 \%$ \\
\hline \multirow[t]{5}{*}{ I.1 } & $\begin{array}{l}\text { Participants with rural place } \\
\text { of residence }^{b}\end{array}$ & & & & \\
\hline & $-\quad 21.05 .2012$ to 31.12 .2012 & 21,900 & $68.5 \%$ & $52.4 \%$ & $17.5 \%$ \\
\hline & $-\quad 01.07 .2013$ to 31.12 .2013 & 15,171 & $77.1 \%$ & $63.0 \%$ & $11.7 \%$ \\
\hline & $-\quad 25.09 .2015$ to 25.09 .2016 & 9,793 & $68.3 \%$ & $53.8 \%$ & $8.4 \%$ \\
\hline & $-\quad 01.10 .2016$ to 30.09 .2017 & 45,342 & $69.0 \%$ & $56.0 \%$ & $7.9 \%$ \\
\hline \multirow[t]{5}{*}{$\mathrm{I} .2$} & $\begin{array}{l}\text { Participants with semi-urban } \\
\text { place of residence }^{b}\end{array}$ & & & & \\
\hline & $-\quad 21.05 .2012$ to 31.12 .2012 & 77,562 & $68.4 \%$ & $51.4 \%$ & $18.4 \%$ \\
\hline & $-\quad 01.07 .2013$ to 31.12 .2013 & 51,639 & $76.0 \%$ & $60.2 \%$ & $14.3 \%$ \\
\hline & $-\quad 25.09 .2015$ to 25.09 .2016 & 37,921 & $68.8 \%$ & $54.0 \%$ & $11.4 \%$ \\
\hline & $-\quad 01.10 .2016$ to 30.09 .2017 & 161,063 & $70.5 \%$ & $57.1 \%$ & $11.0 \%$ \\
\hline \multirow[t]{5}{*}{ I.3 } & $\begin{array}{l}\text { Participants with urban place } \\
\text { of residence }^{b}\end{array}$ & & & & \\
\hline & $-\quad 21.05 .2012$ to 31.12 .2012 & 120,368 & $70.7 \%$ & $54.2 \%$ & $20.5 \%$ \\
\hline & $-\quad 01.07 .2013$ to 31.12 .2013 & 80,315 & $79.4 \%$ & $64.8 \%$ & $17.8 \%$ \\
\hline & $-\quad 25.09 .2015$ to 25.09 .2016 & 58,445 & $72.6 \%$ & $58.7 \%$ & $13.6 \%$ \\
\hline & $-\quad 01.10 .2016$ to 30.09 .2017 & 230,787 & $72.9 \%$ & $60.3 \%$ & $13.6 \%$ \\
\hline II. & $\begin{array}{l}\text { All participants accessing the In- } \\
\text { ternet via mobile radio networks }\end{array}$ & & & & \\
\hline
\end{tabular}

a) Excluding radio-based fixed LTE connections.

b) The distinction of three residence categories is based on the population density in a participant's (self-reported) postal code area. Rural: < 100 inhabitants per sqkm; semi-urban: 100 to 500 inhabitants per sqkm; urban : > 500 inhabitants per sqkm. Sections I.1 to I.3 only report statistics for fixed broadband connections.

c) Internet access via smartphone or tablet, regardless of the type of mobile radio or public WLAN technology standard (e.g., GPRS, UMTS, LTE, IEEE 802.11/WiFi).

Source: Lukas et al., 2013; Lukas et al., 2014; Bundesnetzagentur, 2017a; Bundesnetzagentur, 2018b; author's own analysis 
According to prospect theory, consumers perceive the failure to supply the contractually specified maximum bandwidth as a (psychological) "loss" (Chuang et al., 2012). More frequent losses contribute to a lower experienced value or quality of a service (Stocker \& Whalley, 2018). Thus, an increasing perceived frequency of not getting the contractually mentioned maximum bandwidth under everyday conditions can be expected to coincide with a decrease in customer bonding with the Internet connection provider. Two main arguments can be identified that speak against this proposition. First, customers may be quite aware that the contractual maximal speed is more a theoretical threshold rarely achievable in practice because Internet connection bandwidth actually supplied is a function of a broad set of factors. Such factors include the home's distance to a central office, the capacity utilization of nationwide or international transmission backbones, the processing power of content or application servers addressed or the performance of customer home networks (e.g., Ethernet cabling, WLAN) and terminal devices (e.g., set-top box, laptop, smartphone; cf. Grubesic, 2015; Stocker \& Whalley, 2018). At least in Germany the "regulation on promoting transparency on the telecommunication market" mandates that Internet service providers use so called "product information sheets" and their "general terms and conditions" to expressly make consumers aware that a certain transmission speed is not guaranteed (Gerpott, 2017b). If customers anyway deem contractually agreed maximum bandwidth data irrelevant, then it is unlikely that the frequency of missing of the upper limit value of the speed range of an Internet connection in its everyday use is significantly correlated with the closeness of customers with their access provider because consumers do not equate this undercutting with a seriously harmful "loss".

Second, quite a number of investigations find that the frequency of actually reaching the contractually mentioned maximum bandwidth carries little weight in forming customer connection speed experiences and resultant attitudinal affinity with the provider. Instead, it may be more important to what extent the bandwidth actually supplied is sufficient to ensure the task-oriented functioning of applications with diverging speed requirement such as email, cloud storage or video streaming services (Dabholkar \& Sheng, 2008; Dellaert \& Kahn, 1999; Ryan et al., 2015; Ryan \& Valverde, 2006; Stocker \& Whalley, 2018). This line of reasoning also suggests that the perceived frequency of missing the contractual upper speed limit under standard use conditions and measures of customer bonds with the connection provider should not be strongly correlated.

To the best of our knowledge, with the exception of the four Bundesnetzagentur reports on "true" speed of broadband connections in Germany, there is no prior empirical work that explored correlations between the ratios of actually supplied speeds to contractually agreed maximum bandwidths and customer satisfaction with an Internet connection provider. The Bundesnetzagentur studies conclude that "users who were satisfied with their supplier tended to have obtained a higher percentage of the contractually agreed data transmission rate in the measurement process than users who gave their supplier a poor evaluation" (Bundesnetzagentur, 2018b, 101-102, 155; cf. also similarly Bundesnetzagentur, 2017a; Lukas et al., 2014; Lukas et al., 2013). This result supports the view that customers who are convinced that the bandwidths actually obtained frequently fall below the contractually specified maximum speeds equate their experience with a considerable decrease in service value. This in turn negatively affects the attitudinal bonds of customers with their connection provider. However, none of the four Bundesnetzagentur publications contains precise information on the size of the correlations between speedrelated delivery reliability and customer satisfaction. ${ }^{2}$ Furthermore, the Bundesnetzagentur fails to investigate the (size of the) effect of the degree of speed-related delivery reliability on the propensity of broadband users to continue or to quit their business relation with their present Internet access provider. This is unfortunate because for Internet connection suppliers customer churn propensity is more closely linked to "real" customer actions (and revenues) and thus of greater economic importance than customer satisfaction compared to an attitudinal facet of service provider bonding. With regard to the second reference point of speed-related connection quality assessments, the impression concerning access

2 The relevant graphs in the Bundesnetzagentur investigations at least support the conclusion that the absolute size of the association seems to be rather low. 
bandwidths conveyed to consumers in provider ads, the literature agrees that in many countries suppliers currently design their ads such that they promote unrealistic customer expectations in terms of data rates actually available under routine conditions (ACCC, 2017; Brinkmann, 2013; Bünder \& Jansen, 2018b; Faulhaber, 2010; Hasan et al., 2011; Schamberg, 2015). Hence, broadband connection ads often share many of the characteristics suggested in the literature to identify variants of "deceptive advertising" (Barone \& Miniard, 1999; Boush et al., 2009; Fathy et al., 2016; Riquelme et al., 2016; Xie et al., 2015). Advertisements of a customer's connection provider, which are experienced as overly positive, should also generate (psychological) losses among recipients because customers evaluate this supplier behavior as being unfair (Jha \& Balaji, 2015). However, an open issue is the size of the loss because the severity of harm, which consumers anticipate as a result of being misinformed about the true connection speeds, is not clear (Xie et al., 2015).

Extant empirical research mostly finds that customer perception of "deception [in marketing], regardless of area, can cause a decrease in consumers' satisfaction and trust" (Gillespie et al. 2016). In addition, some empirical studies, which focus on correlations between the perceived veracity of ads of telecommunication network operators and customer bonds to such firms indicate that the detrimental effects of unrealistic ads on customer closeness with the supplier also hold in an telecommunication environment (Fathy et al., 2016; Khan et al., 2015; Shahzad \& Kausar, 2016). However, prior investigations on customer deception in the telecommunications industry have not yet explored customer perceptions of the degree of realism of speed-related claims in ads of Internet connection providers.

Notwithstanding the previously described research gap, the literature overall supports the following position: Experienced frequency of not getting the contractually agreed maximal speed and the perceived degree of bandwidth exaggeration in ads of a customer's connection provider tend to significantly reduce customer attitudinal affinity with the supplier. In this context, it should be noted that the two sources of losses may not have simple additive effects on customer bonding. Rather, according to the prospect theory, the mental utility function for changes of wealth is strongly convex for losses (Kahneman \& Tversky, 1979). This implies that in case of utility reductions caused by Internet access speed experiences below the contractually agreed maximum bandwidth or overblown speed claims in provider ads the remaining second source of relative quality decreases should have a disproportionally negative effect on the subjective total consumer utility of an Internet connection and, consequently, on customer closeness with the supplier. Therefore, we posit the following interaction/moderation hypothesis $(\mathrm{H})$, which can be written in two variants:

$\mathrm{H}_{1 \mathrm{a}}$ : The perceived frequency of not getting the contractually specified maximum connection bandwidth correlates the less negatively with the strength of customer bonds with their access provider the more customers' rate ads of their provider as exaggerated in terms of speed claims.

$\mathrm{H}_{1 \mathrm{~b}}$ : The extent to which customers rate ads of their connection provider as exaggerated in terms of speed claims correlates the less negatively with the strength of customer bonds with their provider the higher the perceived frequency of not getting the contractually specified maximum bandwidth is.

To date, neither scholars nor practitioners have analyzed in greater depth potential correlations between the frequency with which Internet users conduct speed tests for their broadband connection and customer bonds with their supplier. At least for Germany, it is to be assumed that consumers often running speed tests find in most cases that the transmission rates they actually get are far below the maximal bandwidths mentioned in their connection contracts (see Table 1). Hence, on average, more frequent speed testing is likely to reinforce already existing speed-related quality concerns of consumers and, consequently, to decrease the closeness with their access provider. However, it should be kept in mind that customers who are convinced that the actual speed of their Internet connection commonly under- 
cuts the contractually agreed maximum bandwidths may disproportionally reduce the subjective utility of their access through carrying out speed tests more often: More frequent testing reminds this group of consumers of the poor contract-related delivery reliability of their supplier and, accordingly, increases their "losses". On the contrary, for customers with a low concern about the speed-related delivery trustworthiness of their provider more frequent speed tests should not amplify pre-existing worries with regard to the connection quality. Likewise, among customers who experience speed-related claims in ads of their providers as overblown, larger numbers of speed tests strengthen the awareness of the weak ad-related delivery reliability of their supplier. As a consequence, in this customer group more frequent speed testing may reduce the perceived consumer utility from the business relation to a larger extent than in the segment of customers who do not identify exaggerated bandwidth-related promises in advertisements of their provider.

All in all, the preceding considerations lead to the following two interaction/moderation hypotheses:

$\mathrm{H}_{2}$ : The perceived frequency of not getting the contractually specified maximum connection bandwidth correlates the more negatively with the strength of customer bonds with their access provider the more frequently customers conduct connection speed tests.

$\mathrm{H}_{3}$ : The extent to which customers rate ads of their connection provider as exaggerated in terms of speed claims correlates the more negatively with the strength of customer bonds with their provider the more frequently customers conduct connection speed tests.

\section{Empirical methods}

\subsection{Data collection and sample}

The empirical analysis uses data collected by means of a Web-based written highly standardized questionnaire with mainly closed response formats. The survey was open to all German-speaking persons who use a fixed-line broadband connection to access the Internet at their home. Prior to the main study six experts from different Internet service providers and 12 individuals with a wireline broadband connection at home pre-tested the instrument with regard to comprehensibility, clarity and item overlaps. The optimized final field instrument was made publicly available via an Internet link from NOV-152017 to JAN-14-2018. Participation in the study was promoted by placing a note and a link on sites of two German IT magazines and a non-profit organization whose goal is to stand up for "digital liberties". Furthermore, we directed attention to the investigation through notes on various portals and community sites (e.g., Xing). The notes on all sites hosting the link to our instrument emphasized that data collection was strictly confidential and anonymous.

The first page of the survey underlined explicitly that filling in the questionnaire was meaningful only for persons who currently access the Internet over a fixed-line connection at home. The focus on wireline broadband connections (WBC) was chosen because prior work on associations between connection quality perceptions of Internet users and closeness with their service provider is mostly limited to consumers with mobile radio broadband connections to the Internet and excludes people with a fixed-line access (for a review of relevant empirical investigations of subjects with a mobile broadband connection see Gerpott, 2016). ${ }^{3}$ Overall, the data generation efforts resulted in a sample of 934 persons who called up the first page of our instrument and responded to at least one question. 182 of these visitors were discarded because they chose the answer option "don't know exactly" or had completely missing values for all items used to measure the study variables. This procedure resulted in a sample of up to 752 subjects for the analysis presented in this paper. The survey administration software automatically

\footnotetext{
${ }^{3}$ From a theoretical perspective there are no strong arguments against the position that the three study hypotheses should principally also hold true for customers with a mobile radio broadband Internet access. Therefore, the hypotheses were worded without limiting them to a specific network connection technology. For a discussion of potential differences between users with a mobile radio or a fixed-line access see section 5.2 below.
} 
recorded the IP address of the access of each respondent. No two persons had the same IP address. This suggests that it is unlikely that the sample includes participants who filled in the instrument more than once. The access of $97.5 \%$ of the respondents had a German IP address, $2.1 \%$ had an IP address of another European country and $0.4 \%$ of a non-European country. The regional distribution of the IP addresses indicates that nearly all subjects in the sample currently reside in Germany.

Table 2 contains the distributions of the participants' responses concerning the socio-demographic characteristics age, gender, formal educational level and extent of employment. The distributions of the four variables in our sample deviate significantly from the population of persons aged at least 15 years who live in Germany according to the German Federal Statistical Office. Compared to this population our sample includes a disproportionally high share of males who are not older than 45 years, have higher education degree and are fully employed. The socio-demographic structure of the sample seems to suggest that especially IT savvy young men with a higher education degree took part in the investigation. Hence, strictly speaking the present data set allows testing the hypotheses only for this group of WBC users.

$67.1 \%$ of the subjects surveyed stated that Telekom Deutschland or Vodafone (including Kabel Deutschland) or $1 \& 1$ was the provider of their current WBC. Customers of the German incumbent are underrepresented in the sample compared to the entire German WBC market in which Telekom Deutschland achieved a share of $40.5 \%$ at the end of the year 2017 (Dialog Consult \& VATM, 2017). The $15.6 \%$ share of customers of "other" WBC suppliers than the five listed by name in Table 2 (see variable 5) is, by contrast, (too) large compared to a share $9.4 \%$ in the overall market (Dialog Consult \& VATM, 2017). The share of respondents who get their WBC from Vodafone, 1\&1, Unitymedia and Telefónica, respectively, each consistently deviates by less than three percentage points from the corresponding fractions in the total German market.

$26.3 \%$ of the participants stated that their current WBC connection is based on a coax cable access (see variable 6 in Table 2). This share does equally not differ by more than three percentage points from the relevant proportion in the population of private households with a WBC in Germany (Bundesnetzagentur, 2017b; Dialog Consult \& VATM, 2017). With regard to the contractually specified maximum download rate (see variable 7 in Table 2) the share of persons in the sample with a $50 \mathrm{Mbit} / \mathrm{s}$ (100 $\mathrm{Mbit} / \mathrm{s}) \mathrm{WBC}$ is $61.3 \%(29.9 \%)$. This is substantially larger than the corresponding fraction of $28.3 \%$ $(12.6 \%)$ in the population of private households with a WBC in Germany (Bundesnetzagentur, 2017b; Dialog Consult \& VATM, 2017). The present result resembles observations in the four broadband speed studies of the Bundesnetzagentur in which the share of volunteer participants with very high capacity WBC was also far above the fraction in the population (cf. Bundesnetzagentur, 2018b). Hence, it can be presumed that persons with a "very high end" WBC are more inclined to conduct access speed tests and to answer questions concerning their quality experience with their WBC in a scientific survey.

$70.4 \%$ of the subjects included in the study have been customers of their present WBC provider for at least three years (see variable 8 in Table 2). The mean and median of the respondents' tenure with their connection provider amounted to seven and five years, respectively (see variable 4 in Table 5). Accordingly, the quality experiences of the participants are typically based on an extensive period during which they used the connection of their current supplier.

\subsection{Variable measurements}

\subsubsection{Dependent criteria}

The attitudinal bonds of WBC users with their access provider were captured by the two constructs satisfaction with fixed-line connection at home and propensity to churn (as an antipode to a high level of customer affinity with a supplier). To measure satisfaction with the WBC, two items were averaged. 


\section{Table 2}

Sample characteristics

\begin{tabular}{|c|c|c|c|}
\hline 1. Age $(n=573)$ & & \multicolumn{2}{|c|}{ 5. Provider of fixed-line Internet connection } \\
\hline - 15-25 years: & $9.8 \%$ & at home $(\mathrm{n}=752)$ & \\
\hline - 26-35 years: & $32.5 \%$ & - Telekom Deutschland: & $29.0 \%$ \\
\hline - 36-45 years: & $25.0 \%$ & - Vodafone: & $21.3 \%$ \\
\hline - 46-55 years: & $19.5 \%$ & - 1\&1: & $16.8 \%$ \\
\hline - 56-65 years: & $9.4 \%$ & - Unitymedia: & $9.3 \%$ \\
\hline - 66-80 years: & $3.8 \%$ & - Telefónica: & $8.0 \%$ \\
\hline & & - Others: & $15.6 \%$ \\
\hline
\end{tabular}

2. Gender $(\mathrm{n}=558)$
- Female:
$8.2 \%$
- Male:

3. Higher education degree $(\mathrm{n}=581)$

$\begin{array}{ll}\text { - No: } & 48.4 \% \\ \text { - Yes: } & 51.6 \%\end{array}$
4. Extent of employment $(n=576)$

- Not employed:

- Employed part-time:

- Employed full-time:
$19.4 \%$

$14.8 \%$

$65.8 \%$
6. Type of fixed-line Internet connection at home $(\mathrm{n}=718)$

- DSL-access: $\quad 73.7 \%$

- (Coax)Cable access: $\quad 26.3 \%$

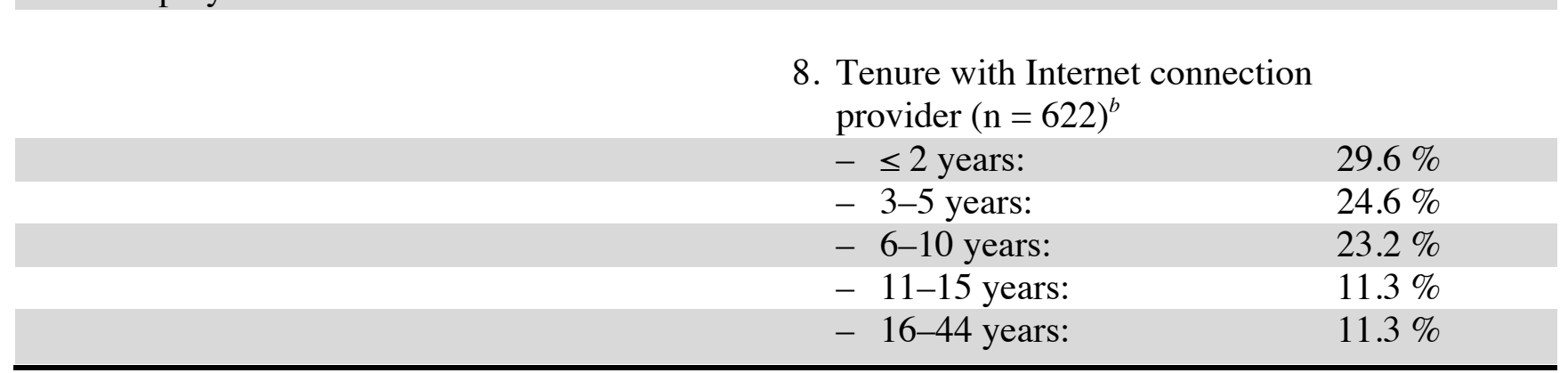

a) The exact wording of the question and the answer categories are documented in footnote $\mathrm{d}$ of table 5. The question and the staged answer options were presented in German and were translated into English for the present article. The same applies for any other question/item used in the empirical section of this paper.

b) Tenure with the Internet connection provider was derived from the response to the following question: "Since when (which year) have you been customer of your current fixed-line Internet connection provider?"

They were taken from instruments of prior surveys of consumers accessing the Internet via mobile radio networks (e.g., Chuah et al., 2017) and adapted to fit the WBC context of the present work. The wording of the items and their four answer options (besides a fifth alternative "don't know exactly") and the scores assigned to the options are documented in footnote a of Table 3. The satisfaction scale achieved an internal consistency reliability (Cronbach $\alpha$ ) of 0.73 , which is above the level of 0.70 commonly taken as the minimum for a sufficiently reliable measurement. As can be seen from Table 3 , $62.7 \%$ of the respondents were "very satisfied" or "rather satisfied" with the WBC of their current provider (scale score $\geq 2.5$ ). The average satisfaction score in our sample amounted to 2.58 ( $\mathrm{SD}=0.90$; see variable I in Table 5 below). Similarly high levels of WBC satisfaction were also detected in the four broadband speed studies of the Bundesnetzagentur. The second facet of (missing) customer bonds with the provider of their WBD, propensity to churn, was measured with an item similar to questions used by Malhotra et al. (2013, 17, item \# 2 of the "propensity to switch" scale) and Lunn \& Lyons $(2017,14)$. The item, its answer options and the scoring of the responses are reported in footnote $\mathrm{b}$ of Table $3.67 .8 \%$ of the subjects stated that it is "very unlikely" or "rather unlikely" that they will terminate their WBC at the next opportunity. The variable mean in the sample was 2.18 (SD = 1.06; see var- 
iable II in Table 3). In interpreting the second criterion, it should be kept in mind that higher values correspond to a lower degree of customer affinity with the provider.

The share of common variance of the satisfaction and the churn intention measures amounts to $20.4 \%$ (see squared correlation between variables I and II in Table 3 below). A principal component factor analysis of the three items used in total to capture facets of customer bonds yielded two factors with high loadings of the two satisfaction items on the first and the cancellation item on the second factor. In light of these results and convincing recommendations in the literature to treat customer satisfaction and (dis)loyalty as distinct aspects of customer bonds with a supplier (see Gerpott et al., 2001), it appears to be justifiable to separately incorporate satisfaction and propensity to churn as dependent criteria in the hypothesis testing.

\section{Table 3}

Frequency distributions of the two facets of customer bonds with connection provider

\section{Satisfaction with fixed-line connection at home ${ }^{a}$}

\begin{tabular}{cccccc}
\hline$<1.5$ & $\begin{array}{c}1.5 \text { and } \\
<2.5\end{array}$ & $\begin{array}{c}2.5 \text { and } \\
<3.5\end{array}$ & Sum & $\begin{array}{c}\text { Don't know } \\
\text { exactly }\end{array}$ \\
\hline 61 & 158 & 200 & 169 & 588 & 9 \\
$(10.4 \%)$ & $(26.9 \%)$ & $(34.0 \%)$ & $(28.7 \%)$ & $(100.0 \%)$ & - \\
\hline
\end{tabular}

a) Mean of the response values of the following two questions: "How satisfied are you with the speed provided by your fixed-line Internet connection at home in the last three months?" and "How satisfied are you with the price-performance ratio of your fixed-line Internet connection at home?" For each question, the answer categories were "very dissatisfied" $(=1)$, "rather dissatisfied" (=2), "rather satisfied" (=3) and "very satisfied" (=4). Internal consistency reliability Cronbach $\alpha=0.73$.

II. Propensity to $\operatorname{churn}^{b}$

\begin{tabular}{|c|c|c|c|c|c|}
\hline 1 & 2 & 3 & 4 & Sum & $\begin{array}{c}\text { Don't know } \\
\text { exactly }\end{array}$ \\
\hline $\begin{array}{c}184 \\
(31.6 \%)\end{array}$ & $\begin{array}{c}211 \\
(36.2 \%)\end{array}$ & $\begin{array}{c}87 \\
(14.9 \%)\end{array}$ & $\begin{array}{c}101 \\
(17.3 \%)\end{array}$ & $\begin{array}{c}583 \\
(100.0 \%)\end{array}$ & $\begin{array}{l}18 \\
-\end{array}$ \\
\hline
\end{tabular}

b) Response to the question "How likely is it that you will terminate your fixed-line Internet connection at the next opportunity?" The answer categories were "very unlikely" (=1), "rather unlikely" $(=2)$, "rather likely" $(=3)$ and "very likely" $(=4)$.

\subsubsection{Prime explanatory variables}

The three variables picked up in the study hypotheses as potential determinants of customer satisfaction with the home WBC and propensity to churn were captured as follows:

Share of Internet sessions below the maximum speeds as specified in a customer's contract. The measure of this relative bandwidth-related quality facet had to be newly developed because usable models are not available in prior work. The variable was operationalized by asking participants to estimate the share of their Internet sessions at home during which they do not get the contractually specified maximum (1) upload and (2) download speeds. Each of the two questions was accompanied by five staged response alternatives plus the escape option "do not know exactly" (see footnote a of Table 4 for details). The Cronbach $\alpha$ internal consistency reliability of the two indicators achieved a satisfactory value of 0.77 . Therefore, subsequently the two items are averaged to measure customer WBC speed experiences relative to formal contractual arrangements. $51.7 \%$ of the subjects who did not select the "do not know exactly" answer for at least one of the two questions state that their share of Internet sessions without getting the contractually named maximal speed was lower than $50 \%$ (scale score $<2.5$ ). Con- 


\section{Table 4}

Frequency distributions of the prime explanatory study variables

\section{Share of Internet sessions without getting the contractually specified maximum speed ${ }^{a}$}

\begin{tabular}{ccccccc}
\hline$<1.5$ & $\begin{array}{c}\geq .5 \text { and } \\
<2.5\end{array}$ & $\begin{array}{c}2.5 \text { and } \\
<3.5\end{array}$ & $\begin{array}{c}\geq 3.5 \text { and } \\
<4.5\end{array}$ & Sum & $\begin{array}{c}\text { Don't know } \\
\text { exactly }\end{array}$ \\
\hline 212 & 82 & 107 & 98 & 69 & 568 & 79 \\
$(37.3 \%)$ & $(14.4 \%)$ & $(18.8 \%)$ & $(17.3 \%)$ & $(12.2 \%)$ & $(100.0 \%)$ & - \\
\hline
\end{tabular}

a) Mean of the response values of two questions: "What is, in your opinion, the share of your Internet sessions at home during which you do not get the contractually specified maximum upload [download] speed?" For each question, the answer categories were "less than $25 \% "(=1)$, "25-49\%" (= 2), "50-74\%" (= 3), "75-99\%" (= 4) and "100\%" (= 5). Internal consistency reliability Cronbach $\alpha=0.77$.

2. Advertised speed typically higher than speed actually supplied ${ }^{b}$

\begin{tabular}{cccccc}
\hline 1 & 2 & 3 & \multicolumn{2}{c}{$\begin{array}{c}\text { Don’t know } \\
\text { exactly }\end{array}$} \\
\hline 167 & 89 & 101 & Sum & 155 & 512 \\
$(32.6 \%)$ & $(17.4 \%)$ & $(19.7 \%)$ & $(30.3 \%)$ & $(100.0 \%)$ & - \\
\hline
\end{tabular}

b) Degree of agreement with the statement "The provider of my fixed-line Internet connection at home particularly emphasizes a higher connection speed in his ads than I am actually typically getting from him at home." The staged answer anchors were "do not agree" (=1), "rather do not agree" $(=2)$, "rather agree" $(=3)$ and "fully agree" $(=4)$.

3. Frequency of conducting speed tests ${ }^{c}$

\begin{tabular}{ccccccc}
\hline 0 & & & & \multicolumn{2}{c}{$\begin{array}{c}\text { Don't know } \\
\text { exactly }\end{array}$} \\
\hline 23 & 1 & 2 & 3 & 4 & Sum & 612 \\
$(3.8 \%)$ & 170 & 98 & 66 & 255 & $(10 \%)$ & - \\
\hline
\end{tabular}

c) Response to the question "How often did you conduct speed tests for your Internet connection at home during the past 12 months?" The answer options were "never" $(=0)$, , 1 to 4 times" $(=1)$, "5 to 8 times" $(=2)$, "9 to 12 times" (=3) and "more than 12 times" (=4).

sequently, $48.3 \%$ of the eligible study participants estimate that the corresponding proportion of sessions during which they did not reach the maximum bandwidth was at least $50 \%$ (see variable 1 in Table 4).

Speed exaggeration in provider advertisements. This quality experience was measured by asking respondents to indicate their degree of agreement with the statement "The provider of my fixed-line Internet connection at home particularly emphasizes a higher connection speed in his ads than I am actually typically getting from him at home." The associated answer categories and their scoring are documented in footnote $\mathrm{b}$ of Table 4 . The item was principally borrowed from previous studies on perceptions of deceptive advertising of users of telecommunication services (e.g., Fathy et al., 2016; Shahad \& Kausar, 2016), but adjusted for the WBC context of the present research. $50.0 \%$ of the 512 subjects with valid answers "rather agree" or "fully agreed" with the statement, whereas $50.0 \%$ chose the response options "rather do not agree" of "do not agree" (see variable 2 in Table 4).

Frequency of conducting speed tests. The relevant empirical literature has not yet considered customer use of applications or tools for checking the bandwidth actually obtained by a consumer when accessing the Internet from home. Therefore, this variable was captured by a self-designed simple direct question that invited participants to state how often they conducted speed tests for their Internet connection at home during the past 12 months. Footnote $\mathrm{c}$ of Table 4 gives information about the response options for this question and their scoring. $3.8 \%$ of the 612 subjects with a substantive answer reported that 
they did not even once perform a speed test of their WBC in the 12 preceding months. By contrast, $41.6 \%$ of the participants indicated that they tested the speed of their WBC more than 12 times over the last 12 months (see variable 3 in Table 4). In line with the findings presented in section 3.1, this result also reveals that our sample is characterized by WBC users with an above average level of interest with respect to the data transmission rates they actually get under everyday conditions from their provider.

\subsubsection{Control variables}

Prior investigations show that the tenure of customers with their current supplier of telecommunication services is significantly correlated with customer satisfaction and the propensity of customers to leave their provider (cf. Kim \& Yoon, 2004; Lunn \& Lyons, 2017; Malhotra \& Kubowicz Malhotra, 2013). Hence, customer tenure with the WBC provider was incorporated as a control variable to make sure that the results of the hypothesis testing are not confounded by this contract-related background characteristic. The variable was computed by subtracting the year in which the customer first signed up with the Internet access service provider from 2018 - the final year of the study period (see variable 8 in Table 2 and variable 4 in Table 5). ${ }^{4}$

\section{Table 5}

Descriptive statistics and bivariate correlations of the study variables

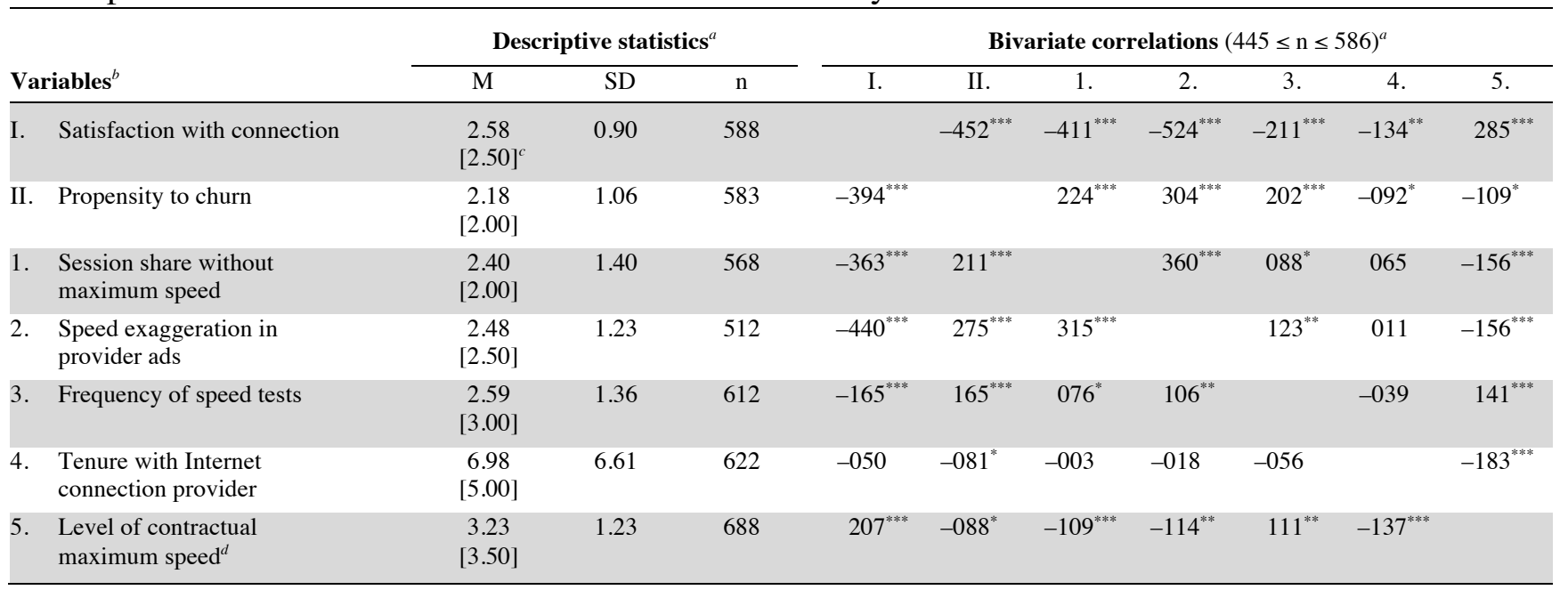

a) $\quad \mathrm{M}=$ Mean. $\mathrm{SD}=$ Standard deviation. $\mathrm{n}=$ number of valid observations. Values above (below) the main diagonal are Pearson product-moment correlations $(r)$. Values below the main diagonal are Kendall rank correlations $(\pi-b)$. Leading decimal is omitted for correlations $(e . g$., $304=0.304)$. Significance levels (two-tailed) of coefficients are flagged as follows: ${ }^{+} \mathrm{p} \leq 0.10^{*} \mathrm{p} \leq 0.05^{* *} \mathrm{p} \leq 0.01{ }^{* * *} \mathrm{p} \leq 0.001$.

b) See Tables 3 and 4 for measurement details of variables I, II and 1 to 3 .

c) Figure in squared brackets below mean = Median.

d) Mean of the response values of two questions: "What maximum download [upload] bandwidth speed is contractually agreed for your fixed-line Internet connection at home?" For each question, the answer options were "<6 Mbit/s" (=1), " $\geq 6 \mathrm{Mbit} / \mathrm{s}$ " (=2), " $\geq 16 \mathrm{Mbit} / \mathrm{s}$ " (= 3$)$, " $\geq 32 \mathrm{Mbit} / \mathrm{s}$ " (= 4), " $\geq 50 \mathrm{Mbit} / \mathrm{s}$ " (= 5), " $\geq 100 \mathrm{Mbit} / \mathrm{s}$ " (=6) and " $\geq 400 \mathrm{Mbit} / \mathrm{s}$ " (=7). Participants who responded to at least one of the two questions by choosing the category "don't know exactly" were discarded. Internal consisting reliability Cronbach $\alpha=0.70$.

In addition, the four broadband speed studies commissioned by the Bundesnetzagentur detected that "customers with connections with higher contractually agreed maximal data transmission rates tend to be more satisfied with their supplier than those with connections with lower contractually agreed maximal data transmission rates" (Bundesnetzagentur, 2017a). Consequently, the level of contractual maximum speed reported by the subjects for their WBC was entered as a second covariate into a part of the regression models calculated to test the study hypotheses. The exact wording of the two averaged items, their response categories and the scoring of the categories are documented in footnote $\mathrm{d}$ of Table

${ }^{4}$ The correlation between the stated initial year of the customer contract with the current WBC provider and the year of birth of a respondent amounts to $0.36(\mathrm{p} \leq 0.001 ; \mathrm{n}=506)$. This significant association may be taken to suggest that the contract-related information given by the subjects is likely to be accurate. 
5. Descriptive statistics and bivariate correlations of the two dependent criteria, the three variables addressed in the hypotheses and the two control variables can also be taken from Table 5.

\section{Empirical results of the hypothesis testing}

The study hypotheses were tested with four multivariate least squares regression models for each of the facets of customer bonds with the WBC provider (see Table 6). All eight regressions explain a statistically highly significant variance share of the WBC satisfaction and propensity to churn measures (see $\mathrm{R}^{2}$-regression figures in Table 6). Thus, on the whole, the various predictor sets in Table 6 capture variance shares of the criteria, which are sufficiently large to proceed with a discussion of the $\beta$-weights of the individual predictors.

\section{Table 6}

Regressions of two facets of customer bonds with connection provider ${ }^{a}$

\begin{tabular}{|c|c|c|c|c|c|c|c|c|}
\hline \multirow[b]{2}{*}{ Explanatory variables } & \multicolumn{2}{|c|}{ Model I } & \multicolumn{2}{|c|}{ Model II } & \multicolumn{2}{|c|}{ Model III } & \multicolumn{2}{|c|}{ Model IV } \\
\hline & $\mathrm{SC}$ & $\mathrm{PC}$ & SC & $\mathrm{PC}$ & SC & PC & SC & $\mathrm{PC}$ \\
\hline $\begin{array}{l}\text { 1. Session share with- } \\
\text { out maximum speed }\end{array}$ & $\begin{array}{l}-256 \\
{[000]}\end{array}$ & $\begin{array}{c}\mathbf{0 9 9} \\
{[055]}\end{array}$ & $\begin{array}{l}\mathbf{- 2 5 2} \\
{[000]}\end{array}$ & $\begin{array}{c}085 \\
{[103]}\end{array}$ & $\begin{array}{l}-194 \\
{[000]}\end{array}$ & $\begin{array}{c}048 \\
{[393]}\end{array}$ & $\begin{array}{l}\mathbf{- 1 8 9} \\
{[000]}\end{array}$ & $\begin{array}{c}051 \\
{[356]}\end{array}$ \\
\hline $\begin{array}{l}\text { 2. Speed exaggeration } \\
\text { in provider ads }\end{array}$ & $\begin{array}{l}-421 \\
{[000]}\end{array}$ & $\begin{array}{c}\mathbf{2 6 5} \\
{[000]}\end{array}$ & $\begin{array}{r}\mathbf{- 4 1 5} \\
{[000]}\end{array}$ & $\begin{array}{c}\mathbf{2 7 1} \\
{[000]}\end{array}$ & $\begin{array}{l}\mathbf{- 3 8 3} \\
{[000]}\end{array}$ & $\begin{array}{c}\mathbf{2 7 8} \\
{[000]}\end{array}$ & $\begin{array}{l}\mathbf{- 3 8 5} \\
{[000]}\end{array}$ & $\begin{array}{c}\mathbf{2 7 9} \\
{[000]}\end{array}$ \\
\hline $\begin{array}{l}\text { 3. Frequency of } \\
\text { speed tests }\end{array}$ & $\begin{array}{l}-106 \\
{[010]}\end{array}$ & $\begin{array}{c}118 \\
{[014]}\end{array}$ & $\begin{array}{l}-\mathbf{1 3 7} \\
{[002]}\end{array}$ & $\begin{array}{c}137 \\
{[008]}\end{array}$ & $\begin{array}{l}\mathbf{- 2 0 7} \\
{[000]}\end{array}$ & $\begin{array}{c}148 \\
{[008]}\end{array}$ & $\begin{array}{l}-\mathbf{1 9 8} \\
{[000]}\end{array}$ & $\begin{array}{c}156 \\
{[003]}\end{array}$ \\
\hline 4. Cross product $1 \times 2$ & - & - & $\begin{array}{c}063 \\
{[125]}\end{array}$ & $\begin{array}{l}-\mathbf{- 1 4 1} \\
{[003]}\end{array}$ & $\begin{array}{c}\mathbf{0 7 2} \\
{[091]}\end{array}$ & $\begin{array}{l}\mathbf{- 1 2 8} \\
{[015]}\end{array}$ & $\begin{array}{c}\mathbf{0 7 0} \\
{[096]}\end{array}$ & $\begin{array}{l}\mathbf{- 1 2 2} \\
{[019]}\end{array}$ \\
\hline 5. Cross product $1 \times 3$ & - & - & $\begin{array}{l}-008 \\
{[846]}\end{array}$ & $\begin{array}{c}029 \\
{[567]}\end{array}$ & $\begin{array}{r}-025 \\
{[584]}\end{array}$ & $\begin{array}{c}042 \\
{[441]}\end{array}$ & - & - \\
\hline 6. Cross product $2 \times 3$ & - & - & $\begin{array}{l}\mathbf{- 1 1 0} \\
{[012]}\end{array}$ & $\begin{array}{c}073 \\
{[151]}\end{array}$ & $\begin{array}{l}-\mathbf{1 4 6} \\
{[001]}\end{array}$ & $\begin{array}{c}074 \\
{[179]}\end{array}$ & $\begin{array}{l}\mathbf{- 1 5 1} \\
{[000]}\end{array}$ & $\begin{array}{c}\mathbf{0 8 9} \\
{[086]}\end{array}$ \\
\hline 7. Cross product $1 \times 2 \times 3$ & - & - & $\begin{array}{c}038 \\
{[384]}\end{array}$ & $\begin{array}{c}002 \\
{[967]}\end{array}$ & $\begin{array}{c}031 \\
{[493]}\end{array}$ & $\begin{array}{c}023 \\
{[681]}\end{array}$ & - & - \\
\hline 8. Tenure with ICP & - & - & - & - & $\begin{array}{l}-\mathbf{- 1 1 5} \\
{[007]}\end{array}$ & $\begin{array}{l}-\mathbf{- 1 1 6} \\
{[026]}\end{array}$ & $\begin{array}{l}\mathbf{- 1 1 6} \\
{[006]}\end{array}$ & $\begin{array}{l}-\mathbf{1 1 5} \\
{[027]}\end{array}$ \\
\hline $\begin{array}{l}\text { 9. Level of contractual } \\
\text { maximum speed }\end{array}$ & - & - & - & - & $\begin{array}{c}\mathbf{2 2 2} \\
{[000]}\end{array}$ & $\begin{array}{l}\mathbf{- 1 6 3} \\
{[002]}\end{array}$ & $\begin{array}{c}223 \\
{[000]}\end{array}$ & $\begin{array}{l}\mathbf{- 1 6 3} \\
{[002]}\end{array}$ \\
\hline $\mathrm{R}^{2}$-regression & $\begin{array}{c}\mathbf{3 5 8} \\
{[000]}\end{array}$ & $\begin{array}{c}126 \\
{[000]}\end{array}$ & $\begin{array}{c}375 \\
{[000]}\end{array}$ & $\begin{array}{c}152 \\
{[000]}\end{array}$ & $\begin{array}{c}\mathbf{4 5 1} \\
{[000]}\end{array}$ & $\begin{array}{c}195 \\
{[000]}\end{array}$ & $\begin{array}{c}449 \\
{[000]}\end{array}$ & $\begin{array}{c}193 \\
{[000]}\end{array}$ \\
\hline $\begin{array}{l}\text { Maximum variance in- } \\
\text { flation factor }\end{array}$ & 1.197 & 1.198 & 1.226 & 1.227 & 1.232 & 1.232 & 1.227 & 1.227 \\
\hline $\begin{array}{l}\text { Number of valid } \\
\text { observations }\end{array}$ & 401 & 394 & 401 & 394 & 334 & 328 & 334 & 328 \\
\hline
\end{tabular}

a) $\mathrm{SC}=$ Satisfaction with connection. $\mathrm{PC}=$ Propensity to churn. ICP $=$ Internet connection provider. The table documents the first three decimals of the standardized $\beta$-weights ( $\mathrm{R}^{2}$-statistics and significance levels) of the explanatory variables (total regression). Example: $-256=-0.256$. $\beta$-weights and $\mathrm{R}^{2}$-values are printed in bold in case that their level of significance is $10 \%$ or better. In order to avoid distortions of the estimates of the cross product terms (predictors 4 to 7) as a result of severe multicollinearity problems, we followed recommendations of Cronbach (1987) and Aiken \& West (1991) and centered variables 1 to 3 before entering them into a regression. Accordingly, cross product terms 4 to 7 were computed with the centered predictors 1 to 3 . Details on the measurement of the variables can be taken from Tables 2 to 5 .

The first regression model determines the partial main effects of the study's prime explanatory factors (see model I in Table 6). According to model I, an increase in the perceived speed exaggeration in provider advertisements coincides with a significantly lower satisfaction level and a higher propensity to churn (see predictor 2 in Table 6). The unique contribution of the speeds experienced relative to formal

5 The scale construed from stated level of contractual maximum upload and download speeds is significantly correlated with the monthly subscription price of the WBC as reported by the participants $(\mathrm{r}=0.33 ; \mathrm{p} \leq 0.001 ; \mathrm{n}=603)$. This significant association suggests that the information on maximal download and upload WBC speeds given by the subjects is presumably correct. 
contractual arrangements to explaining the two customer bonding criteria is somewhat smaller compared to perceived speed overselling. The $\beta$-weights of predictor 1 in model I are highly significant for customer satisfaction $(\mathrm{p} \leq 0.001)$ and marginally significant $(\mathrm{p} \leq 0.055)$ for propensity to quit. In model I predictor 2 has $\beta$-weights for both criteria which are highly significant at $p \leq 0.001$ (two-tailed). Participants with an above average frequency of speed testing were significantly less satisfied and more inclined to churn than respondents who rarely conducted bandwidth tests for their Internet connection at home (see model I, variable 3 in Table 6).

Regression model II furthermore incorporates the three first order interactions and the second order interaction of the prime study variables. The third regression equation differs from model II through additional inclusion of the two control variables. In model II, the cross product of the predictors "session share without maximum speed" and "speed exaggeration in provider ads" achieves a level of statistical significance of $9.1 \%$ and $1.5 \%$ for the satisfaction and the propensity to churn criterion, respectively (see model III, variable 4 in Table 6).

The $\beta$-weights of the interaction term "session share without maximum speed" and "frequency of speed tests" and the second order cross product approach an acceptable level of statistical significance neither in model II nor in model III (see variables 5 and 6 in Table 6). In contrast to this, in models II and III the cross product of the factors "speed exaggeration in provider ads" and "frequency of speed tests" predicts additional variance shares of the satisfaction criterion, which are statistically significant at the $1.2 \%$ - and $0.1 \%$-level, respectively (see variable 6 in Table 6 ). On the other hand, the $\beta$-weights of this interaction term are much smaller and at best achieve an error probability (two-tailed) of $15.1 \%$ in the equations II and III, in which propensity to switch is the dependent variable.

For the sake of model parsimony, predictors 5 and 8 were eliminated in the fourth regression model of Table 6 because their weights were low in absolute terms $(<0.05)$ and by far not statistically significant. In model IV the interaction of the variables "session share without maximum speed" and "speed exaggeration in provider ads" reaches a 9.6\%-level of significance for WBC satisfaction and of $1.9 \%$ for propensity to churn (see variable 4 in Table 6). Besides, in model IV the cross product of the factors "speed exaggeration in provider ads" and "frequency of speed tests" achieves a level of significance of $0.1 \%$ for WBC satisfaction and of $8.6 \%$ for propensity to churn (see variable 6 in Table 6).

In order to facilitate the interpretation of the cross products in Table 6 which are significant at $\mathrm{p}<$ 0.096 or better, Fig. 1 graphs the mean values of WBC satisfaction and propensity to quit measures in the sample for four groups of participants. The groups were formed by classifying subjects depending on whether their personal scores on the two variables comprising a cross product term fell below or not below a certain cut-off value (for more details see footnotes b to $\mathrm{c}$ of Fig. 1). The upper half of Figure 1 reveals that the experienced session share without maximum speed is more negatively (positively) correlated with WBC satisfaction (propensity to churn) criterion if the perceived speed exaggeration in provider advertisements is low. On the contrary, in case that the experienced degree of speed exaggeration in provider ads is high, an increase in the perceived session share without maximum speed has hardly any negative (positive) effect on WBC satisfaction (propensity to churn). Hence, our findings support $\mathrm{H}_{1 \mathrm{a}}$ and $\mathrm{H}_{1 \mathrm{~b}}$ with an error probability of $1.9 \%$ and $9.6 \%$ for propensity to churn and WBC satisfaction, respectively.

In comparison, $\mathrm{H}_{2}$ has to be rejected in our sample given that the $\beta$-weights of predictor 5 in regression equations II and III show levels of significance, which by far do not meet accepted standards.

The lower half of Figure 1 illustrates that an increase in experienced speed exaggeration in provider advertisements is more (less) likely to be accompanied by lower WBC satisfaction and higher propensity to churn if customers carry out bandwidth tests more (less) frequently. This finding confirms $\mathrm{H}_{3}$. 

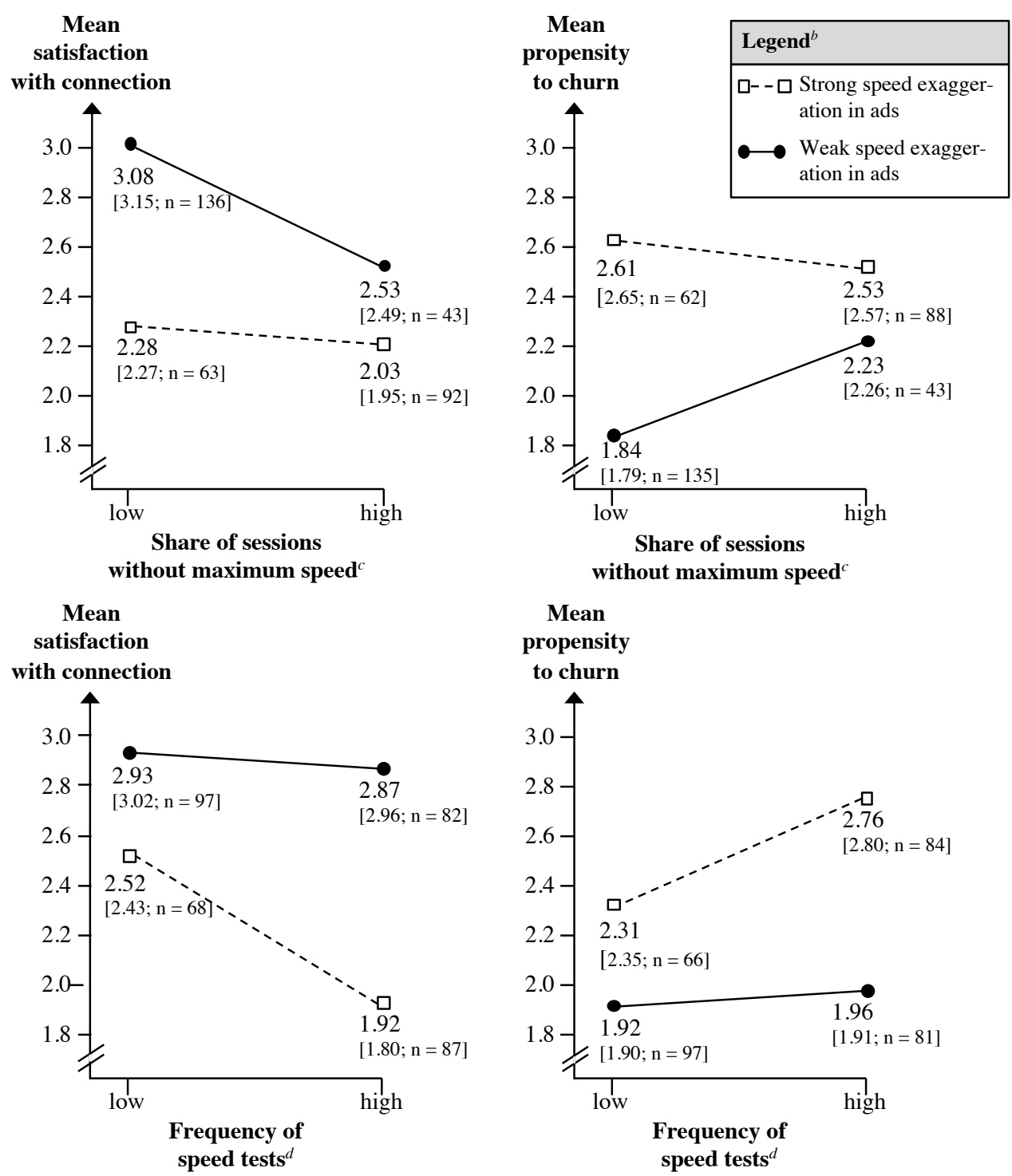

a) The graph displays regression estimates of the subgroup means of the dependent variable in case that variables 3 ( 1 , respectively), 8 and 9 of Table 6 take their average value. Additionally, the original subgroup means before partialling the effects of the three covariates are shown in squared brackets. $n=$ number of valid observations.

b) Weak exaggeration: Predictor value $\leq 2$. Strong exaggeration: Prediction value $>2$. See variable 2 in Table 4 .

c) Low share of sessions without maximum speed: Predictor value $\leq 2.5$. High share of sessions without maximum speed: Predictor value $>2.5$. See variable 1 in Table 4 .

d) Low frequency of speed tests: Predictor value $\leq 3$. High frequency of speed tests: Predictor value $=4$. See variable 3 in Table 4.

Fig. 1 Visualization of significant interaction effects of the prime study variables on the two facets of customer bonds with connection provider ${ }^{a}$

With a view to the control variables, Table 6 indicates that longer tenure with the current WBC provider coincides with lower satisfaction, but also lower propensity to churn values (see variable 8 in Table 6). This result speaks in favor of the assumption that long-term customers, although their satisfaction with their WBC provider is below average, do not switch to a competitor simply for reasons of convenience. The second control variable, level of contractual maximum WBC speed is likewise significantly correlated with the two criteria: Customers who were subscribed to WBC with a larger maximum speed potential are significantly more satisfied with their provider and less inclined to terminate their WBC contract than their counterparts who use a connection with a lower maximum bandwidth. This finding suggests that customer expectations concerning WBC capabilities do not increase proportionally with the contractually specified maximal bandwidth. In other words, higher WBC speeds raise the probability that a connection meets the requirements of consumers and therefore contributes to strengthening customer bonds with their provider. We ran several robustness checks of the findings in Table 6. First, 
we entered four additional socio-demographic control variables (age, gender, level of formal education, current house-hold income) and the network type (see variable 6 in Table 2) into the regression equations. None of the new variables achieved statistical significance $(p>0.30)$. Correspondingly, this variation of the analysis did not materially affect any of the $\beta$-weights presented in Table 6 . Second, regression models III and IV were supplemented by squared values of the (mean-centered) control variables to explore whether their association with the criteria follows, as suggested by Stocker \& Whalley (2018), an inverted U-shaped pattern. For both dependent variables, none of the squared terms passed established significance standards $(\mathrm{p}>0.40)$. Therefore it can be concluded that in the present sample the relations between the two control variables on the one hand and WBC satisfaction and propensity to churn on the other hand are linear. Finally, we ran ordinal regressions, which - unlike the least squares models in Table 6 - do not require interval-scaled and normally distributed variables. This modification yielded results that were substantively identical to the findings shown in Table 6. In summary, the supplementary analyses suggest that the outcomes of the hypothesis tests are unlikely to be an artifact of the statistical procedures underlying the baseline results in Table 6.

\section{Discussion and implications}

The present investigation of a sample of up to 752 German-speaking persons who access the Internet via a WBC at home reveals that the satisfaction of customers with their access provider and customer propensity to terminate a WBC contract increases and decreases, respectively, the higher the contractually specified absolute maximal speed of a connection is. However, the findings also make clear that the degree of affective bonding of customers with their Internet access provider is additionally strongly influenced by two relative speed-related WBC quality aspects (customer experiences concerning the actually received bandwidth compared to contractually mentioned maximal data rates and to access speeds highlighted in ads of their provider). The impression that a customer's WBC does not supply the maximum bandwidths emphasized in ads of the access provider in turn adversely affects the bonds of customers with their connection provider to a larger extent than perceptions of the share of one's Internet sessions during which the contractually fixed maximum bandwidths are not supplied. Thus, in calibrating customer assessments of the speed-related quality of their Internet access, bandwidth-related WBC advertising claims appear to play a stronger role than upper limit bandwidth values hidden somewhere in a customer's access contract papers. According to our results, the bonding effects of the two recorded relative WBC speed evaluations are not always additive: If either speed-related advertising claims of a customer's connection provider are perceived as overblown relative to the actually received bandwidths or the share of Internet sessions, during which the contractually specified maximal data rate is reached, is rated as low, then the effects of the other bandwidth experience factor on customer bonds with the connection provider are mitigated. Besides, more frequent speed tests contribute toward less intense customer bonds with the WBC provider, particularly in case that speed-related advertising claims are experienced as excessively positive.

\subsection{Practical implications}

Our findings carry several important implications for the design of marketing activities of WBC providers. The empirical results suggest that WBC suppliers should refrain from highlighting transmission speed ceilings in their market communication (e.g., advertisements, service fact sheets, general terms and conditions) that customers, for whatever reason, very rarely or even never reach under routine use conditions. In case that Internet access providers, for competitive reasons, want to continue to prioritize maximum bandwidth data in their market communication, then they should definitely at least report realistically calculated shares of Internet sessions for which customers may expect to really get the contractual maximal speed. However, providers are typically better of if they put "normally" available down- and upload transmission rates at the heart of their speed-related quality messages. A promising way to vividly convey the level of a supplier's delivery reliability in terms of bandwidths is to quantify probabilities that consumers at least reach normally available speed thresholds under everyday circum- 
stances and to clearly present the respective figures to the market. Estimates of such likelihoods may be derived from recent network load data and should be set conservatively to counteract unfulfilled expectations among customers.

From a policy perspective the results indicate that WBC sellers should actively support initiatives aiming at an industry-wide (self-) regulation of broadband speed claims in advertisements such as, for instance, the guidelines published by the Committee of Advertising Practice (CAP) in the UK or by the Australian Competition \& Consumer Commission (ACCC). Relevant industry bodies mostly recommend that ads should provide WBC subscribers with accurate information about typical speeds that an average consumer on a broadband plan can expect to receive (ACCC, 2017; CAP, 2017). Adherence to guidelines like this may help to promote realistic speed expectations and feelings of justice among WBC customers. It cannot be excluded that a promotion strategy, which refrains from "whitewashing" connection speed information, causes short-term decreases in the number of newly acquired customers. However, it also has the likely effect to lower the share of newly won customers, who terminate their WBC contract already after a short time because of disappointed speed expectations. Furthermore, it has the mid-term potential to increase the proportion of buyers who recommend the Internet service provider to other consumers because they feel to be treated fairly.

Moreover, to reduce exaggerated speed expectations of users, WBC providers and consumer protection organizations alike should step up their efforts to explain clearly to Internet users that their WBC speed experiences do not only depend on the capacity of public telecommunications networks but also on a range of other factors, which private households can partially influence themselves. In this process, WBC providers in particular could support their customers with briefing information on how consumers ought to design their home networks and to select their terminal devices in a way that promotes the achievement of the desired speed experiences when accessing the Internet at home (Stocker \& Whalley, 2018).

At least in Germany, $\S 8$ of the "regulation on promoting transparency on the telecommunication market" of DEC-19-2016 makes it mandatory that providers of Internet access services expressively inform private consumers about the possibility of running online tests for measuring actually available data transmission rates of $\mathrm{WBC}$ at home at least twice upon conclusion of the contract and after activating the WBC (Gerpott, 2017b). Following our results, from a WBC provider's point of view repeatedly prompting existing customers to test the speed of their access once the connection is activated, is not a priority. Such tests seem to raise the sensitivity of consumers to variations in WBC quality parameters and increase the probability that consumer expectations regarding the bandwidths of their Internet connection are not met. Hence, suppliers should motivate customers to repeatedly test the data rates of their WBC at most if they are highly confident that the shares of their customers who will actually get the "normally available" and "maximal" transmission rates emphasized in sales campaigns are much higher than that of competitors.

\subsection{Limitations and resulting implications for future research}

The present investigation contributes to the literature on quality aspects of WBC by supplementing valuable work on the supply situation of WBC differentiated according to contractual maximal speeds at which WBC are advertised at national, regional or local levels (e.g., Grubesic, 2015). Our study is the first to analyze WBC bandwidth experiences of (German-speaking) private customers relative to contractually agreed upper speed limits and advertising claims of a consumer's provider as correlates of the degree of customer bonding with Internet access suppliers. Nevertheless, in spite or because of the innovative character of the analysis, it is not without limitations. Three constraints are particularly noteworthy because they point to worthwhile directions for further scholarly research. 
First, the empirical results are based on an opportunity sample of up to 752 individuals, who are not representative for the population of adult Internet users with a WBC at home in Germany. Rather, it is quite likely that the respondents are predominantly persons with an above average (critical) awareness of the down- and upload ceilings of their home WBC. This sample composition could imply an overestimation of the weight of the two WBC speed perceptions in shaping consumer bonds with their access provider. Hence, it is desirable to replicate our work in customer samples, which better match the relevant population in Germany in terms of socio-demographic characteristics and maximal speed of their WBC. Similarly, surveys of consumers from other countries with a less tight speed-related WBC transparency regulation than in Germany will help to explore to what extent the present findings are influenced by national differences in consumer protection rules.

Second, the investigation focuses on fixed wireline broadband connections at home. Consumers who access the Internet via mobile radio networks with a smartphone or tablet while being on the move were not considered. At least in Germany compared to consumers with WBC at home, mobile Internet users commonly get speeds, which fall much further and more often below contractually agreed maximal data transmission rates and the bandwidths stressed in ads of their network provider (see Table 1). Therefore, speed disappointment experiences (in relation to contract terms or ad claims) could be larger and have stronger impacts on attitudinal bonds with their provider among mobile users than in case of consumers with a WBC. On the other hand, indoor and outdoor network coverage is an additional quality facet of radio-based broadband connections, which is not a matter of importance for WBC (Gerpott, 2016). Consequently, the perceived delivery reliability with respect to maximum speeds specified in customer contracts or in supplier ads could have weaker effects on customer bonds among mobile consumers than among users who access the Internet with a WBC at home. Thus, future work should include users of a mobile broadband connection to explore which of the two positions finds empirical support.

Finally, the study's measures are all based on self-assessments of consumers with WBC at home. This may lead to inflated estimates of associations between constructs because of „,common method biases“ (CMB; Podsakoff et al., 2003). Against this background, we placed questions capturing the various study variables in different parts of the survey instrument as a precautionary measure to reduce halo effects. Furthermore, as a second remedy against CMB, the wording and number of answer categories used in measuring the study variables were varied. In addition, as suggested by Podsakoff et al. (2003), we ran two ex post checks for CMB (Harman's single factor test; directly measured latent factor analysis). Both procedures revealed that CMB does not severely threat the validity of our conclusions. Finally, the larger power of the predictors in explaining the satisfaction criterion $\left(R^{2}\right.$ values in Table 6 range from 0.36 to 0.45$)$ in comparison to the propensity to churn variable $\left(\mathrm{R}^{2}\right.$ values in Table 6 range from 0.13 to 0.19 ) is also an indication that CMB should not be a major issue in our work. Nevertheless, longitudinal multi-method studies are still needed, which capture reference-dependent WBC speed experiences prior to measurements of customer bonds with their access provider and which include behavioral criteria such as "real" contract terminations by WBC customers in addition to behavioral intentions. Such investigations may also refine our measurement of the experienced gap between contractual and received speed by not only looking at the frequency with which consumers perceive this gap, but, in addition at experienced differences between contractual and received bandwidths, i.e., the size of the discrepancy.

\section{References}

ACCC (2017). Broadband speed claims (August 2017, version 1). Brisbane: Australian Competition \& Consumer Commission. Retrieved from <https:/www.accc.gov.au/system/files/CCS\%20-\%20Broadband\%20Speed $\%$ 20Claims \%20-\%20Industry\%20guidance \%20-\%20FINAL\%20ex\%20SCB\%2018\%20Aug\%202 ....pdf>. 
Aiken, L.S., \& West, S.G. (1991). Multiple regression: Testing and interpreting interactions. Newbury Park: Sage.

Barone, M. J., \& Miniard, P. W. (1999). How and when factual ad claims mislead consumers: Examining the deceptive consequences of copy x copy interactions for partial comparative advertisements. Journal of Marketing Research, 36(1), 58.

Boush, D.M., Friestad, M., \& Wright, P. (2009). Deception in the marketplace. New York: Routledge.

Brinkmann, B. (2013). Internet langsamer als von Anbietern versprochen. Süddeutsche.de Digital, 11.4.2013. Retrieved from <http://www.sueddeutsche.de/digital/bericht-der-bundesnetzagentur-internet-langsamer-als-v on-anbietern-versprochen-1.1646805>.

Bünder, H., \& Jansen, J. (2018a). Mobilfunkkunden zahlen zu viel für langsames Internet. Frankfurter Allgemeine Zeitung, 18.1.2018, No. 15, 22.

Bünder, H., \& Jansen, J. (2018b). Der große Breitbandschwindel. Frankfurter Allgemeine Zeitung, 13.2.2018, No. 37, 21.

Bundesnetzagentur (2017a). Breitbandmessung Jahresbericht 2015/16. Bonn: Bundesnetzagentur. Retrieved from <https://www.bundesnetzagentur.de/SharedDocs/Downloads/DE/Sachgebiete/Telekommunikation/Verb raucher/Breitbandmessung/Breitbandmessung_Jahresbericht_\%202015_2016.pdf?_blob=publicationFile\&v $=2>$.

Bundesnetzagentur (2017b). Tätigkeitsbericht Telekommunikation 2016/2017. Bonn: Bundesnetzagentur. Retrieved from <https://www.bundesnetzagentur.de/SharedDocs/Downloads/DE/Allgemeines/Bundesnetzagentur/P ublikationen/Berichte/2017/TB_Telekommunikation20162017.pdf?__blob=publicationFile\&v=3>.

Bundesnetzagentur (2018a). Breitbandmessung. Bonn: Bundesnetzagentur (17. Jan. 2018). Retrieved from $<$ https://www.bundesnetzagentur.de/DE/Sachgebiete/Telekommunikation/Verbraucher/Breitbandmessung/Br eitbandmessung-node.html>.

Bundesnetzagentur (2018b). Breitbandmessung Jahresbericht 2016/17. Bonn: Bundesnetzagentur. Retrieved from <https://www.bundesnetzagentur.de/SharedDocs/Downloads/DE/Sachgebiete/Telekommunikation/Verb raucher/Breitbandmessung/Breitbandmessung_Jahresbericht_\%202016_2017.pdf?_blob=publicationFile\&v $=3>$.

Buoye, A. (2016). An examination of relative satisfaction and share of wallet: Investigating the impact of country and customer characteristics. Journal of Service Theory and Practice, 26(3), 297.

CAP (2017). Broadband speed claims: Advertising guidance (non-broadcast and broadcast) (23 Nov. 2017). London: Committee of Advertising Practice \& Advertising Standards Authority. Retrieved from <https:// www.asa.org.uk/uploads/assets/uploaded/2fb48b59-c087-470c-8ff2a39b6fe2cd7f.pdf>.

Chuah, S. H. W., Marimuthu, M., Kandampully, J., \& Bilgihan, A. (2017). What drives Gen Y loyalty? Understanding the mediated moderating roles of switching costs and alternative attractiveness in the valuesatisfaction-loyalty chain. Journal of Retailing and Consumer Services, 36, 124.

Chuang, S. C., Cheng, Y. H., Chang, C. J., \& Yang, S. W. (2012). The effect of service failure types and service recovery on customer satisfaction: A mental accounting perspective. The Service Industries Journal, 32(2), 257.

Cronbach, L. J. (1987). Statistical tests for moderator variables: Flaws in analyses recently proposed. Psychological Bulletin, 102(3), 414.

Dabholkar, P. A., \& Sheng, X. (2008). Perceived download waiting in using web sites: A conceptual framework with mediating and moderating effects. Journal of Marketing Theory and Practice, 16(3), 259.

Dellaert, B. G., \& Kahn, B. E. (1999). How tolerable is delay?: Consumers' evaluations of Internet web sites after waiting. Journal of interactive marketing, 13(1), 41.

Dialog Consult, \& VATM (2017). 19. TK-Marktanalyse Deutschland 2017. Düsseldorf: Dialog Consult (18. Okt. 2017). Retrieved from <http://www.dialog-consult.com/pdf/Dialog_Consult_Newsletter_201701.pdf $>$.

Elkins, E. (2018). Powered by Netflix: Speed test services and video-on-demand's global development projects. Media, Culture \& Society, 40(6), 838.

Fathy, D., Elsharnouby, T. H., \& Aish, E. A. (2016). Deception in advertising revisited: Antecedents and differences in perception across consumer groups. International Journal of Business and Emerging Markets, 8(4), 403. 
Faulhaber, G. R. (2010). Transparency and broadband Internet service providers. International Journal of Communication, 4(1), 738.

FCC (2016). Measuring broadband America: Fixed broadband report. Washington: Federal Communications Commission. Retrieved from <http://data.fcc.gov/download/measuring-broadband-america/2016/2016-FixedMeasuring-Broadband-America-Report.pdf $>$.

Gerpott, T. J. (2016). Management von Kundenzufriedenheit in der Mobilfunkbranche. In: Homburg, C. (Ed.), Kundenzufriedenheit (9th ed.), Wiesbaden: Springer Gabler, 459.

Gerpott, T. J. (2017a). Regulierung der Mindestqualität von Internetzugangsdiensten. Netzwirtschaften \& Recht, 14(3-4), 143.

Gerpott, T. J. (2017b). Informationsbereitstellung für Verbraucher bei Internetzugangsdiensten. Kommunikation \& Recht, 20(6), 378.

Gerpott, T. J., Rams, W., \& Schindler, A. (2001). Customer retention, loyalty, and satisfaction in the German mobile cellular telecommunications market. Telecommunications Policy, 25(4), 249.

Gillespie, E. A., Hybnerova, K., Esmark, C., \& Noble, S. M. (2016). A tangled web: Views of deception from the customer's perspective. Business Ethics: A European Review, 25(2), 198.

Giovanis, A. N., Zondiros, D., \& Tomaras, P. (2014). The antecedents of customer loyalty for broadband services: The role of service quality, emotional satisfaction and corporate image. Procedia - Social and Behavioral Sciences, 148, 236.

Gneezy, A., Gneezy, U., \& Lauga, D. O. (2014). A reference-dependent model of the price-quality heuristic. Journal of Marketing Research, 51(2), 153.

Grubesic, T. H. (2015). The broadband provision tensor. Growth and Change, 46(1), 58.

Grzybowski, L., Hasbi, M., \& Liang, J. (2018). Transition from copper to fiber broadband: The role of connection speed and switching costs. Information Economics and Policy, 42(1), 1.

Hasan, S. A., \& Subhani, M. I. (2011). Effects of deceptive advertising on consumer loyalty in telecommunication industry of Pakistan. Information Management and Business Review, 3(5), 261.

ITU (2017). The state of broadband: Broadband catalyzing sustainable development. Genf: International Telecommunication Union. Retrieved from <https://www.itu.int/dms_pub/itu-s/opb/pol/S-POL-BROADBAND.1 8-2017-PDF-E.pdf>.

Jha, S., \& Balaji, M.S. (2015). Perceived justice and recovery satisfaction: The moderating role of customerperceived quality. Management \& Marketing, 10(2), 132.

Kahneman, D., \& Tversky, A. (1979). Prospect theory: An analysis of decision under risk. Econometrica, 47(2), 263.

Khan, S.K., Saeed, N., Feroz, M., Liaqaut, S., Khan, A., \& Jabeen, Z. (2015). Impact of deceptive marketing on consumers behavior: A case of cellular industry of Pakistan. Journal of Marketing and Consumer Research, 18(1), 91 .

Kim, H. S., \& Yoon, C. H. (2004). Determinants of subscriber churn and customer loyalty in the Korean mobile telephony market. Telecommunications Policy, 28(9-10), 751.

Klingbeil, L. (2017). Interview Netzfragen zur Bundestagswahl. Telepolis Onlinemagazin für Politik \& Medien im digitalen Zeitalter (2. Sep. 2017). Retrieved from <http://www.heise.de/-3820058>.

Klink, J., Podolska, M. J., \& Uhl, T. (2012). Regulatory framework and technical aspects of broadband access to the Internet in Europe. 2nd Baltic Congress on Future Internet Communications. Vilnius: IEEE. DOI: 10.1109/BCFIC.2012.6217980. Retrieved from <http://ieeexplore.ieee.org/stamp/stamp.jsp?tp=\&arnumber=6 217980>.

Lukas, K., Marks, A., Schöttler, B. O., \& Sudhues, C. (2013). Abschlussbericht "Dienstequalität von Breitbandzugängen “. Ismaning: Zafaco. Retrieved from <https://www.bundesnetzagentur.de/SharedDocs/Downloads/ DE/Sachgebiete/Telekommunikation/Verbraucher/Breitbandmessung/Qualitaetsstudie/AbschlussberichtQuali taetsstudie2012.pdf?_blob=publicationFile \&v=2>.

Lukas, K., Marks, A., Schöttler, B. O., \& Sudhues, C. (2014). Abschlussbericht „Dienstequalität von Breitbandzugängen II“. Ismaning: Zafaco. Retrieved from <https://www.bundesnetzagentur.de/SharedDocs/Downloads /DE/Sachgebiete/Telekommunikation/Verbraucher/Breitbandmessung/Qualitaetsstudie/AbschlussberichtQual itaetsstudie2013.pdf?_blob=publicationFile \&v=3>. 
Lunn, P. D., \& Lyons, S. (2017). Customer switching intentions for telecoms services: Evidence from Ireland. Dublin: MPRA Paper No. 77412 (10. Mar. 2017). Retrieved from <https://mpra.ub.uni-muenchen.de/77412/1 /MPRA_paper_77412.pdf>.

Malhotra, A., \& Kubowicz Malhotra, C. (2013). Exploring switching behavior of US mobile service customers. Journal of Services Marketing, 27(1), 13.

Mansmann, U. (2009). Grob geschätzt - Online-Speedtests arbeiten ungenau. c't magazin für computer technik, $27(8), 157$.

Ofcom (2016). Ofcom broadband and mobile checker app. London: Office of Communications (16. Dec. 2016). Retrieved from: <https://www.ofcom.org.uk/phones-telecoms-and-internet/advice-for-consumers/advice/ofco m-checker>.

Ofcom (2018). UK home broadband performance. London: Office of Communications (9 May 2018). Retrieved from: <https://www.ofcom.org.uk/_data/assets/pdf_file/0027/113796/home-broadband-2017.pdf>.

Quach, T. N., Jebarajakirthy, C., \& Thaichon, P. (2016). The effects of service quality on Internet service provider customers' behaviour: A mixed methods study. Asia Pacific Journal of Marketing and Logistics, 28(3), 435.

Podsakoff, P. M., MacKenzie, S. B., Lee, J. Y., \& Podsakoff, N. P. (2003). Common method biases in behavioral research: A critical review of the literature and recommended remedies. Journal of Applied Psychology, $88(5), 879$.

Reuter, M. (2018). Breitbandmessung: Wenn deine Internetverbindung ein Backofen wäre. Berlin: Netzpolitik.org (18. Jan. 2018). Retrieved from <https://netzpolitik.org/2018/breitbandmessung-wenn-deine-internetv erbindung-ein-backofen-waere/>.

Riquelme, I. P., Román, S., \& Iacobucci, D. (2016). Consumers' perceptions of online and offline retailer deception: A moderated mediation analysis. Journal of Interactive Marketing, 35, 16.

Ryan, G., del Mar Pàmies, M., \& Valverde, M. (2015). WWW= Wait, wait, wait: Emotional reactions to waiting on the Internet. Journal of Electronic Commerce Research, 16(4), 261.

Ryan, G., \& Valverde, M. (2006). Waiting in line for online services: A qualitative study of the user's perspective. Information Systems Journal, 16(2), 181.

Schamberg, J. (2015). Urteil zur Internetgeschwindigkeit: Auch "bis zu"-Werbung kann irreführend sein. Onlinekosten.de (14. Nov. 2015). Retrieved from <https://www.onlinekosten. de/news/urteil-zur-internetgeschwin digkeit-auch-bis-zu-werbung-kann-irrefuehrend-sein_202558.html>.

Shahzad, M., \& Kausar, M. (2016). The influence of deceptive advertising on customer trust and loyalty. Umeå: School of Business and Economics. Retrieved from <http://www.divaportal.org/smash/get/diva2:952451/FU LLTEXT01.pdf>.

Stocker, V., \& Whalley, J. (2018). Speed isn't everything: A multi-criteria analysis of the broadband consumer experience in the UK. Telecommunications Policy, 42(1), 1.

Telekom Deutschland (2018). Leistungsbeschreibung MagentaZuhause (Stand: 01.01.2018). Bonn: Deutsche Telekom. Retrieved from <https://www.telekom.de/dlp/agb/pdf/44910.pdf>.

Thaichon, P., Lobo, A., Prentice, C., \& Quach, T. N. (2014). The development of service quality dimensions for Internet service providers: Retaining customers of different usage patterns. Journal of Retailing and Consumer Services, 21(6), 1047.

Xie, G. X., Madrigal, R., \& Boush, D. M. (2015). Disentangling the effects of perceived deception and anticipated harm on consumer responses to deceptive advertising. Journal of Business Ethics, 129(2), 281.

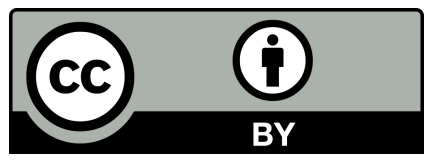

(C) 2018 by the authors; licensee Growing Science, Canada. This is an open access article distributed under the terms and conditions of the Creative Commons Attribution (CCBY) license (http://creativecommons.org/licenses/by/4.0/). 